UJBM, Vol. 3, No. 1, January - June 2004, pp 1-18

ISSN 0975-3311 | https://doi.org/10.12725/ujbm.4.1

\title{
BUSINESS TURNAROUND: LOOKING FROM A DIAGNOSTIC VIEW
}

\author{
Sunita Panicker*
}

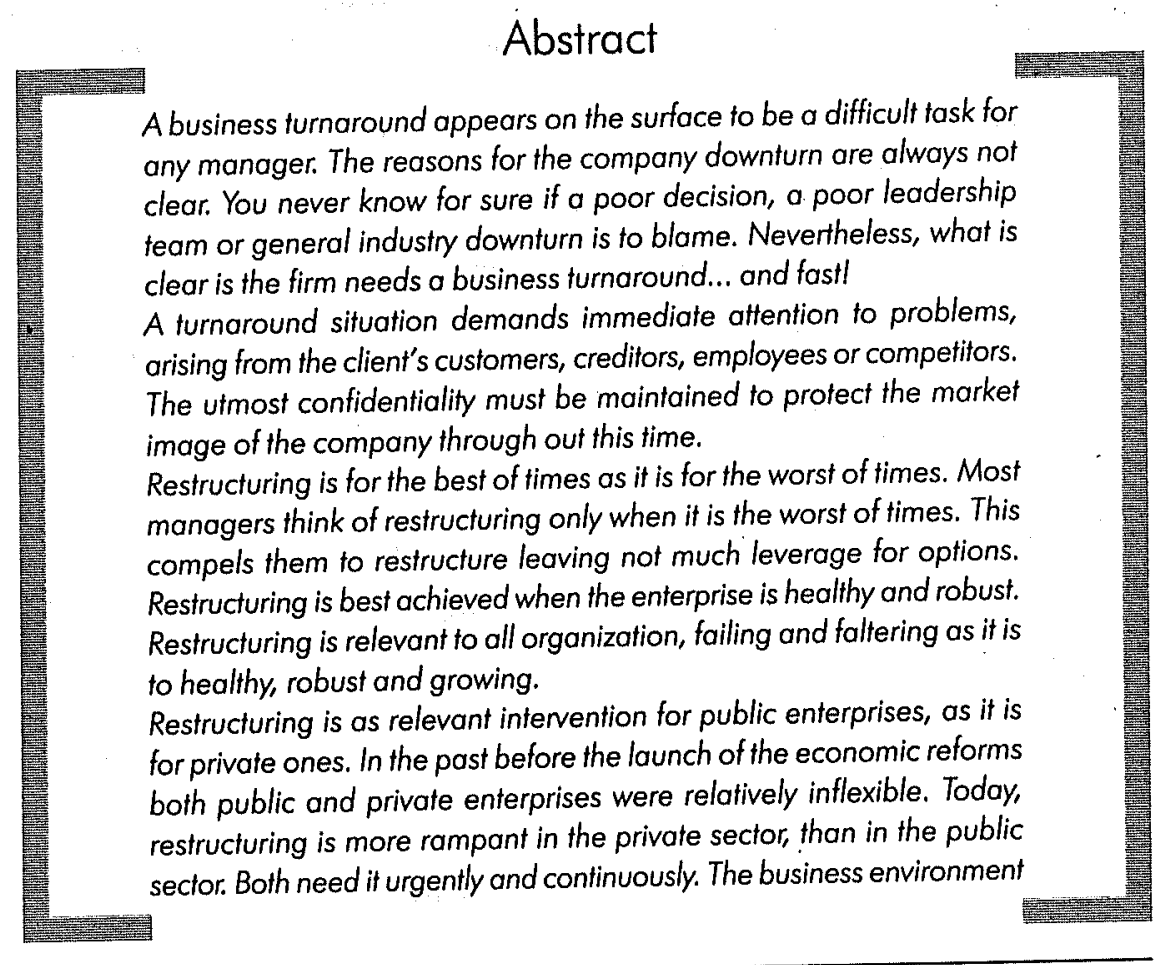

* Lecturer, Department of Management Studies, Christ College, Bangalore. 
metamorphosed by globalisation. IT and Telecom has made restructuring necessary for survival. Sickness had wider ramifications. One must look at the problem from a diagnostic angle. There are various stages of turnaround, which is prescribed by Turnaround Management Association for successful turnarounds. The turnaround strategies adopted by various companies will give us insight into the success of a company.

Industries are an integral part of a nation's economy. In a dynamic set up industrial units which are non-competitive, uneconomical and inefficient become sick and dieout as new and more efficient units come up to take their place. This process takes place due to structural adjustment programme executed by the Government of India, as suggested by WTO. Reallocation of resources, both material and human, from less efficient to more efficient areas is not only expected to increase production and productivity but also will lead to higher employment generation in the long run. Has this reform of Government of India brought about any change in the status of industrial sickness? Industrial sickness creates problem of wanting financial resources, puts a burden on banks and also enhances the public expenditure.

The information compiled by RBI from scheduled banks over years is shown below:

\section{Table 1}

\section{Industrial Sickness in India}

\begin{tabular}{|c|c|c|c|}
\hline End & Large and Medium & Small & Total \\
\hline Dec-80 & 1401 & 23149 & 24550 \\
\hline Sep-92 & 2427 & 233441 & 235868 \\
\hline Mar-96 & 2374 & 262376 & 264750 \\
\hline Mar-97 & 2368 & 235032 & 237400 \\
\hline Mar-98 & 2476 & 221536 & 224012 \\
\hline Mar-99 & 2792 & 306221 & 309013 \\
\hline Mar-01 & 3317 & 249630 & 252947 \\
\hline
\end{tabular}

Source: RBI 
Table 2

Industrial sickness in India

Outstanding Bank Credit (Rupees in crores)

\begin{tabular}{|c|c|c|c|}
\hline End & Large and Medium & \multicolumn{1}{|c|}{ Small } & Total \\
\hline Dec-80 & 1502 & 306 & 1808 \\
\hline Sep-92 & 9241 & 3346 & 12587 \\
\hline Mar-96 & 10026 & 3722 & 13748 \\
\hline Mar-97 & 10178 & 3609 & 1377 \\
\hline Mar-98 & 11825 & 3857 & 15682 \\
\hline Mar-99 & 15150 & 4313 & 19463 \\
\hline Mar-00 & 17705 & 5951 & 23656 \\
\hline Mar-01 & 21269 & 4506 & 25775 \\
\hline
\end{tabular}

Source: RBI

There were 252947 sick/weak units in March 2001 consisting of 249630 units in SSI sector and 3317 units in the other sector (Table 1). The total bank credit blocked in sickunits has increased from 23656 crore as on March 31, 2000 to Rs. 25775 crore as on March 31, 2001 (Table 2).

The trend has proved that the liberalisation and globalisation has done nothing to combat the industrial sickness phenomena over years. The trend in fact widens the gap. There are several reasons for industrial sickness as observed by the researchers and industrialists over years. The sickness is due to two factors. They are endogenous and extrogeneous in character. The extrogeneous factors relate to factors like government policies pertaining to production, distribution and prices; changes in the investment pattern following the priorities in the plans; shortage of power; transport; raw materials; deteriorating industrial relations, etc. The above factors are likely to affect all units in an industry. These factors deserve corrective action at the territory level by both the state and central Governments. The endogenous factors are mismanagement, diversion of funds, wrong dividend policy, lack for provision of depreciation on machinery and other equipment, over-estimation of demand, etc. The most important causes of sickness in industries is the incompetence and the inefficiency of the management. Globalisation has changed the boundaries. Satellite television and the Internet have unified the world's consumers. In the superhighway of globalised environment, some existing industries are subject to survival struggle due to the competitive edge of multinational corporations. Western society 
has developed cushions to absorb the shock of business closures, but developing economies are not fully equipped to face such challenges. Industrial sickness was on the rise in India during the 1990s.

According to the Reserve Bank of India, an industrial unit is considered financially sick if one or more of the following symptoms are observed.

i. Accumulated losses eating away the net worth.

ii. Sharp increase in debt/equity ratio.

iii. Default in paying taxes

iv. Decline in share prices

v. Disappearance of margin of loans

vi. Failing to stick to schedules to repay loans and interest.

vii. High potential costs, reducing profits

viii. No further financial assistance from lending institutions under normal conditions

ix. Problems of working capital management and chronic shortage of funds and complete lack of liquidity on operations.

The main reasons for company failure are:

- Inability to cope with dumping from foreign manufacturers, consequent to the removal of tariff barriers.

- Income-generating capacity being constrained by a system of administered selling prices.

- Changes in Government regulations.

- Loss of market share through poor product-quality and faulty pricing policies.

- Unrelated diversification affecting core competencies.

- Product obsolescence.

- An inflexible or incompatible Chief Executive Officer (CEO), who refuses to identify the problems but blames them on external factors, could be a serious handicap to any turnaround process.

- Failure of existing business plans and strategies and the failure to recognize warning signals in time. If the decline is to be checked, strategies will have to be changed quickly so that there is no further loss. 


\section{Dealing with industrial sickness:}

The basic deficiency in dealing with industrial sickness is that industrial sickness is treated as a financial problem where the concern of labour are by and large ignored. One of the important reasons why the process of restructuring is prolonged and industrial sickness is allowed to continue is because of closure of establishments entails retrenchment of workers.

One of the useful ways of dealing with the problem of industrial sickness is to provide the pre-requisites for growth of production and productivity. The longerterm impacts of liberalisation of industry in the public and private sector leading to retrenchment or redeployment of excess labour poses a very big problem for the success of the reforms.

There is a view point that the mis-match between wage and productivity in the organised sector is one of the important reasons for industrial sickness, lack of competitive edge, loss of business, slow down in exports and adoption of labour saving devices have resulted in jobless growth. Therefore, adequate measures should be taken to increase production and productivity so that there would not only be an expansion of employment opportunities but the real wage would also grow in a sustained manner along with industrial growth. The unions and the management should share their experiences regarding workers participation in management, investment in $\mathrm{HRD}$, etc.

Non-performing assets in the Banking system suggest that the problem of NPA has a sizeable overhang component arising from infirmities in the existing processes of debt recovery, inadequate legal provisions on foreclosure and bankruptcy. This calls for immediate corrective steps in recovery processes so that the problem is contained. Preparing for the Tenth plan would pose testing challenges for Indian Industry. As per the projections of the approach to the Tenth plan, in order to attain the target of $8 \%$ growth of GDP envisaged for the plan period, industry is required to grow at over $10 \%$, especially in an environment of heightened competition from imports following the removal of quantitative restriction.

\section{Sickness and Restructuring:}

Restructuring, more often than not, is equated with turnaround. One way to look at the problem of sickness is the depth of sickness defined by the deviation from the Break-even point. Another way to view the problem is by the "slack theory". Corporates acquire flab when they are doing well. Often, it occurs because 
considerable amount of liquidity has been generated and the management feels that it can afford to be progressive.

The Government appointed a committee on industrial sickness and corporate restructuring which submitted its report in July 1993. The Goswami report was critical of functioning of BIFR. If found that as of July 1992 the BIFR, recommended winding up of only 242 companies out of 1010 cases referred to it and succeeded in turning around only 49 cases.

Restructuring is just business renewal. It can be either total or partial. It can be structural, strategic or operational. Transformation of corporate vision, which may involve change in work culture.

- Technology substitution and upgradation

- Strategic change involving expansion, diversification, and integration backward or forward hiving off.

- Corporate renewal: encompassing intra-corporate reorganisation.

- Leveraging capital, right-sizing capital or rationalising capital resource.

- Human resource revamp: involving right-sizing or establishing new relationships or developing and realigning new skills.

- Functional rationalisation involving business process reengineering including organisational restructuring.

- Market restructuring which may include changes of product mix, product development, re-segmentation or new competition thrust

- Cost reduction focusing on asset structure or operating costs.

\section{Major issues crying for Attention}

- How do we distinguish between revivable and non-revivable enterprises?

- What are the options available for non-revivable enterprises?

- Is it possible to merge the non-revivable enterprises with other units?

- If yes, what will be the fast-track mechanism?

- How can sick companies waiting to be furned around (or closed) attract worker support and co-operation? 
- What are the priorities for revival units?

- What strategy can be adopted for sick companies which cannot stand-alone or are vulnerable units to be left alone to be forced to terminal sickness?

- If Irrevivable sick companies and sick companies with incipient sickness are to be revived where will the funding come from?

- What are the strategies to deal with non-revivable sick companies and revivable sick companies which call for immediate intensive care treatment?

- How does privatization on disinvestment programme affect the future and future course of action of non-perforrning sick companies.

Most of the issues can be addressed by turnarourid strategie:

\section{Four Business Turnaround strategies that you can apply immediately:}

A business turnaround appears on the surface to be a difficult tosk for any manager. The reasons for the company downturn are always unclear. You never know for sure if a poor decision, a poor leadership team or general industry downturn is to blame. Nevertheless, what is clear is the firm needs a business turnaround ... and fast. These strategies help us to identify the common obstacles, making the critical decision and who to turn to for help and maintain profitability. We can use these strategies to rebuild and restructure companies:

\section{Dusiness Turnaround Strategy \# One - Cash control}

The key to this strategy is never to pay out more than you have. What you must do is immediately take control of the cash. This means that every expenses is approved and signed. You will likely have to stretch vendors, but most will understand if you communicate with them about your dire circumstances.

\section{Business Turnaround Strategy \# Two - Immediate downsizing}

Within the next few weeks, you must make some immediate cuts in your operations. This is especially true if you are running out of cash. Since you have an emergency, you cannot spend much time analyzing. Our advice is "Check your gut, and make the cut". 


\section{Business Turnaround Strategy \# Three - Business Model Change}

Once you are reasonably certain that you make payroll over the next few months, then you need to take a strategic view of your firm. You need to discover the profitable areas of your company. These areas then form the foundation of your strategy. To restructure effectively, you must rebuild around profitable business units, products and customers. You must cut everything else.

\section{Business Turnaround Strategy \# Four - Sell the Business}

You will know that you have turned your company around if you have six quarters of profits and cash flow. If you want to sell your business, now is the time. Your firm is now growing and healthy. Buyers will pay a premium for this.

During the furnaround process, it is better to break down the task ahead into small measurable steps and then progress one step at a time. The immediate goals are per force modest. Only after the first milestone is achieved can the company aspire to reach the second milestone which, in all probability, will call for a re-assessment of potential and ability. The mission, therefore, necessarily evolves over a period of time. It needs constant updating and refocusing based on the experience gained during the early days, when the first few rehabilitation initiative deliver positive results. The CEO must find a talent pool from within, as sick companies may not attract outside talent. De-layering and computerized information systems give the CEO the opportunity to interact at all levels to build a team.

\section{Stages of a Turnaround}

Increasing competition, changes in the financial markets and economic volatility have created a climate where not a single business can take economic stability for granted. Even the once-stable companies find it difficult to maintain profitability. It is imperative to understand what it takes to complete a successful corporate furnaround.

Turnaround Management Association outlines the following critical stages of a successful turnaround:

\section{Stage 1: Replacing Top Management}

Most CEOs do not relinquish power easily. Often their egos make it hard for them to admit such a downturn is really happening or that they are unable to pull the 
company out of its nose-dive. After hiring a turnaround specialist steps should be taken to replace top manager or weak board members who might impede the turnaround process and to put into place a top management team who will most successfully lead the turnaround effort.

\section{Stage 2: Analyzing the situation}

Before a turnaround specialist makes any major changes he/she must determine the chances of the business survival, identify appropriate strategies and develop a preliminary action plan.

Once major problems and opportunities are identified a turnaround professional develops a strategic plan with specific goals and detailed functional actions. This must be presented to all key parties in and outside the company.

\section{Stage 3 : Implementing an emergency action plan}

If the company is in a critical stage an appropriate action plan must be developed to stop the bleeding and enable the organisation to survive. The plan typically includes financial, marketing and operational actions to restructure debts, improve working capital, reduce cost, improve budgeting practices, correct pricing, prune product line and accelerate high potential products.

\section{Stage 4: Restructuring the business}

Once the bleeding has stopped, the losing division sold off and administrative cost cut, turnaround efforts should be directed rowards making remaining operations as effective and efficient as possible. This may require further restructuring to increase profits and return on assets and equity.

\section{Stage 5: Returning to normal}

In the final stage of the turnaround process, the company should show signs of profitability. While earlier steps concentrated on correcting problems, stage five focuses on profitability, return on equity and enhancing economic value addition.

The final step cannot be successful without a psychological shift as well. Rebuilding momentum and morale is almost as important as rebuilding the Return on Investment (ROI). It means a rebirth of corporate culture and transforming the negative attitudes to positive, confident ones as the company maps out its future. 


\title{
Judging the Success or Failure of a Turnaround:
}

\begin{abstract}
Of course, not all turnaround succeed in the manner outlined here. A Company may put a quick end to its disastrous losses but never quite attain an acceptable return position. When this occurs, management may decide to sell the business to a company better able to produce an acceptable return on the funds invested. On the other hand, the furnaround may be so successful that the company becomes a target of a takeover bid. In either scenario, the turnaround manager plays a key role in identifying prospective purchasers or analyzing the takeover prospect, and then negotiating a successful sale. Western society had developed cushions to absorb the shock of business closures, but developing economies are not fully equipped to face such challenges. The developing countries have to find a workable strategy to furn around the under-achieving or sick companies.
\end{abstract}

\section{Turnaround Insights:}

Given the strong brand image, new product launches and a good distribution network, the good growth rate recorded by the newly launched sundrop range of footwear for women is likely to help improve the company's profitability in the near
term.

Traded at Rs. 142.5 now, the stock price discounts the latest earning 26 times. The Indian company has come a long way since 1995 when it made a loss of over Rs. 50 crores. In 1998 it returned to the dividend-paying list after four years. The turnaround in Bata's performance was achieved mainly through a continued focus on introducing new and affordable products, better product line, cost control and efficiency in manufacturing and marketing operations. Before this turnaround, the company's focus was on premium segment. In 1996, it refocused its strategy to high volume and low and medium priced segments.

When the JK fiber plant opened in 1989 in Jhalawar, India to manufacture acrylic fibre, it was realization of Plant Director Rampathi Singhania's vision. Singhania wanted to create a company culture of openness, equitable relationships, and minimal bureaucracy. Consultants helped him design a plant that put into practice new thinking about open organisations and participate management. Yet the forwardlooking JK fibre did not become a role for Indian companies to emulate. Some 2.5 years after the plant's opening, production was at $50 \%$ capacity, quality was poor, and moral was abysmal. Worst of all, customers were leaving. 
The original consultants who helped design the plant presented management with a proposal for a whole-system transformation. JK fibre achieved a dramatic turnaround in just 7 months by following a 3-pronged strategy;

1. Corrective-action teams

2. Communication and

3. Leadership management

Corrective action teams: The management set up corrective-action teams to improve plant operations. A CAT is an eight to twelve member cross-functional team that is designed to solve quality and systems problems quickly. A corrective action team would meet for a day or two to analyze a specific problem such as excessive moisture in the fibre or the frequent breakdown of electronic control systems. After determining the root cause of the problem, the team would identify at least four possible solutions, crate a plan, assign tasks, and begin solving the problem. Employees enjoyed serving on corrective action teams because of the satisfaction they got from solving long-standing problems.

Communications : The communications strategy was a systematic learning strategy designed to improve the interaction of departments, functions and systems. From the beginning of JK fibre, communication was encouraged. Now it is imperative. Once a month; managers had always invited all employees to speak with them openly about factory problems and to suggest solutions. Now, managers started meeting daily instead of monthly.

The increased discussion helped break down invisible walls between departments. Managers started to understand the inter relatedness of their functions. Decisions made collectively took into account the needs and requirements of all the departments. Before, managers were preoccupied with the performance of their own departments.

Leadership Development: The company invested the most financially in leadership developments - a transformative learning strategy to turn the company around. Managers, supervisors, and team coordinators participated in learning laboratories to cultivate transformational leadership styles. In addition, they learned to incorporate personal development into their leadership. In leadership development program, people learned the skills that enable them to solve problems as part of a team and to help create a better work environment. Many managers reported that the personal development training not only improved their leadership skills, but also produced more peace and harmony within their families. 
The Vijaypat Singhania group is a working on turnaround for Raymond Synthetics Ltd., to prevent it from being declared a sick company. The Rs. 482 crore Raymond Synthetics has eroded a major portion of its networth, and is likely to become a 'potentially sick company' based on its performance in 1998-99.

The company has been severely affected on account of the poor offtake and low realizations in the polyester filament yarn industry over the last two years.

According to industry sources, financial institutions have asked the promoters of Raymond Synthetics to work out a restructuring package. Various options are being suggested to the company by Financial Institutions. One of the options suggested is a merger of Raymond Synthetics with the Rs. 1,295 crore Raymond L.t.

KHAITAN Paper Machines Ltd., (KPML) has been declared sick by the Board for Industrial and Financial Reconstruction (BIFR) in terms of Section $3(1)(0)$ of SICA. In view of there being no substantial objections from any secured creditors regarding the sickness of the company, the Bench declared the company sick.

"In these circumstances a proposal in terms of Section 17(2) of the Act was not considered feasible and it would be necessary in public interest to explore the provisions of Section 18 of the Act in relation to the company," the Bench said. Accordingly, in terms of the powers available under Section 17(3) of the Act, the Bench appointed IDBI as the operating agency $(O A)$ with directions to conduct TEV study of KPML and prepare a report and revival scheme. IDBI has been directed to keep in view the provisions of Section 18 of the Act.

The Textile Ministry's move to seek alternative routes to the closure of the functioning but unviable six jute mills under the National Jute Mills Corporation (NJMC) is prompted by making it a test case for future tackling of sickness in industries run by the Government, besides protecting the interests of workers. The undertakings of the six jute mills, viz., National, Kinnison, Khardah, Alexandra, Union and RBHM, the management of which were earlier taken over by the Government under the Industries (Development \& Regulation) Act, 1951, were nationalized and vested in NJMC. These mills produced traditional jute goods such as hessian, sacking, jute twine and also jute carpet backing cloth (CBC).

The sources said that even though NJMC was referred to BIFR since August 1992, it held on February 23, 2001, that NJMC was unlikely to make its networth positive within a plausible time, while coping with all its financial commitments. BIFR, accordingly, directed that a show-cause notice be issued to the holding company for its winding up. 
After the poll-time exercises, it is time for textile workers and their trade unions in Tamil Nadu to shake off their fiesta and turn to reality. They are to pick up the thread where they have left last if they were to relaunch their struggle for wage revision, a pending issue or securing the State Government support to revival of the closed textile mills.

The textile trade unions, particularly those affiliated to the communist parties which fought in alliance with the AIADMK, are enthused over the victorious AIADMK supremo Ms Jayalalitha's promising remarks on the efforts needed to reopen the closed mills/industrial units in the State. With over 85 textile mills under the organised sector in the State remaining closed in the last two years due to industrial sickness, the ways and means to revive them should engage the attention of the new State Government shortly taking over the reigns in the coming days, the trade unions feel.

In view of the continued problems faced by the Small Scale Industries sector, Associated Chambers of Commerce and Industry of India (Assocham) has suggested that a regulatory authority or a commission be set up to eliminate sickness among Small Scale Industries.

The proposed regulatory authority should identify sitting judges at different levels and designate those courts to work as agencies of the authority. This will empower the courts with more composite authority to view sickness in industry, its revival or recovery in a more holistic and speedy manner.

It should take steps for changing laws, rules, policies and organise a framework covering all aspect of sickness in industries. The authority would also have a study cell to conduct research and collect data on various aspects of sickness in industries. According to a paper prepare by Assocham, it is time the Government took a positive stand on arresting the sickness in small scale sector.

The Andhra Pradesh Government has spiked a suggestion from some sections in the small-scale industry (SSI) sector for introduction of statutory provisions for the revival of sick units on the lines of the BIFR. This suggestion had been voiced by sections in the State SSI sector for quite some time in view of the persisting sickness the State's small enterprises segment.

In its recently released new policy for the SSI sector, the State Government, replying to the suggestion, expressed the feeling that statutory provisions for the revival of sick units on the lines of BIFR might not be suitable for the small-scale sector in view of the "much larger number of units involved, as also the need for much greater flexibility in dealing with the SSI sector." 
The loss estimated to be $\$ 20.5$ million ( $\$ 15$ million) compared with a net profit of $\$ 57$ million in the same quarter last year - will increase pressure on Clariant chief executive Roland Loesser to present a credible turnaround strategy for the beleaguered group when it reports on Tuesday. The aborted US venture, Clariant's biggest investment project, was supposed supply Proctor \& Gamble with detergent ingredients. Clariant said that at the time it would have to take a write-down of $\$ 120$ million.

A sale of the two business would leave the company focused on textiles, leather and paper, pigments and additives, and functional chemicals. But analysis have said it is unlikely that the disposals will raise enough to allow Clariant to cut its net debt to its target of $\$ 2.5$ billion by the end of the year. One analyst said last week that the company would be lucky to get more than $\$ 650$ million for the businesses that appeared to be on the block. Most analysts see the company raising fresh capital next year. Analysts said the most likely sell-off candidate was the financially troubled Vroom \& Dressmann department store chain, which Vendex has been trying to turn around. In July, Vendex predicted that V.\& D's 2003 operating loss on retail activities could balloon as much as 50 million ( $\$ 57$ million). More details on a turnaround strategy are expected Sept. 9, when Vendex releases half-year results.

CEO Michael Kagan declined to estimate during a 45 minute conference call Wednesday with investors and analysts how much the clothing manufacturer expects to save by moving fabric-cutting operations to the Dominican Republic and Honduras.

"We've lost a lot of money last year, and we're in the midst of a turnaround," Kagan responded. "I can assure you that we are not complacent about what is happening here. We are actively doing whatever we can to turn this company around."

Kagan told analysts and investors that Tropical is exploring whether to sell its cutting facility, which is off Waters Avenue next door to its new corporate headquarters building.

David W. Lichtenstein, president and chief executive officer of privately held Lightstone, was one of Prime's largest shareholders before the acquisition. He said Prime Retail was fragmented in the past by too many classes of shareholders and large amounts of debt, up to $\$ 1.2$ billion in 2000 .

As part of a turnaround strategy during the past three years, the company has been selling shopping centre and refinancing mortgages to pay down debt. [Glenn D. Reschke] said the company has only a couple of malls on the market now. It will 
now focus on improving existing malls by adding more "entertainment" options, such as cinemas and eateries, he said.

Analysts said the outlet mall industry in general is overbuilt, prompting many centers to seek to redefine themselves. The largest outlet mall operator is Chelsea Property Group Inc. of Roseland, N.J., with 58 properties.

Gateway which has lost money in eleven of the past 12 quarters in 2003 , is basing its turnaround strategy on selling more consumer electronics gear, which has higher profit margins than computers. It introduces more than 100 new products last year, many of them aimed at electronics. Moreover, Dell \& HP have turned their sights to markets that Gateway had marked as its own for more than a year, such as flat panel Televisions. Dell is now selling flat-panel Televisions and HP is expected to announce its own lineup.

\section{Common Characteristics of a Successful Turnaround}

\section{Changed culture:}

Organisations facing distress are unwilling to change existing practices. In addition, communications are stilted, and the organisation generally dysfunctional. A successful turnaround creates an environment of free-flowing communication as a result of embedded processes, improving and profit-accountability.

\section{Refocus to cash flow enhancement:}

Cash flow enhancement is the mantra in restructured organisations. Weekly cash flow measure, investment, inventories, collections of receivables, and expenses of supporting customers all are institutionalized in restructured companies. Employee training enhanced. To focus on Return on Investment and Return on Earnings. Incentive compensation is used liberally to trumpet successes when achieving preestablished goals.

\section{Disciplined Management:}

Implementing the strategic plan, including the annual plan, becomes the most important component of Management competencies are well understood, and market share and competitive analyses allow the company to dominate its position. Improved communication management team members results because common goals become clearly established. 


\section{Revitalised workforce:}

Employees surviving a restructuring are married to the organisation. They believe in the products or services offered to customers, have a clear sense of direction of the organisation. Cross-functional teams provide improved understanding of different areas. And effective customer and award systems create meaningful incentives.

\section{Customer/market focus:}

Ultimately, a successful restructured organisation turns its entire focus to meeting customer needs on a profitable basis. Products and services designed to meet customer expectations are planned through active research and development activities. Competitive analysis are important diagnostic and marketing information concerning the competitive landscape. New producls and services are successfully introduced as a better customer communication and market intelligence.

\section{Business Exit Strategies}

If a successful turnaround is not probable, alternatives must be considered and a course of action chosen that yields the most benefit to all involved. Owners of small businesses with personal guarantees outstanding frequently can avoid total financial ruin by choosing the correct course of action and managing the process properly.

Based on your situation we can determine the best course of action in conjunction with your legal counsel and financial advisor to guide you through the process, play an active role in it or manage it for you.

The various exit alternatives as follows:

\section{Sale or Merger}

If sufficient liquidity cannot be generated to support a turnaround period and the conclusion has been reached to cease operations, the sale or merger of your business is always an option provided time is available. We can assist with blind approaches to a variety of possibly interested parties including competitors of choice. Options for selling only portions of the business can also be explored.

\section{Managed Liquidations:}

The least expensive alternative generally yielding the greatest return to all parties involved. This process is carried out by management in the absence of a legal 
format. This works well when the obligations of a company are not extremely complex. The process allows for the greatest amount of control and must be administered in a fair manner and well documented, this option should generally be considered near the top of the list of alternatives.

\section{Assignment for the beneficial interest of Creditors:}

In most states this process is allowed and defined by law but carried on outside of the judicial system. All assets and liabilities are turned over to a third party for disposition. That party will liquidate all assets and distribute the proceeds to all creditors on a prorated basis. Less expensive and faster than a formal bankrupt procedure while allowing substantially more flexibility and greater returns. Again this process must be handled properly and requires some pre-negotiation to be successful.

\section{Bankruptcy:}

If all other options have been exhausted then a form of bankruptcy is required. Within one hundred and twenty days of filing, a formal plan reorganization must be submitted to the court for approval, this time period can be extended in some cases. Although bankrupt should only be considered when no other options are available, it is sometimes required to get necessary assistance from the concerned authorities both pre and post petition. Careful planning will result in most advantageous outcome for all involved.

\section{Conclusion}

Corporate failure is as much a fact of life as death or taxes. But a failing company does not have to be written off with a requiem; it can be nursed back to life by a good turnaround strategy. Companies have been known to transform themselves into strong, profitable enterprises after a turnaround, but the strategy adopted varies from case to case. Company failures have become increasingly identifiable with such unrelated business affecting their core competence. Many companies discover that business in which they had a stranglehold for several years are threatened by global competition, which is striking at the root of their existence. Banks have a pivotal role to play in accelerating the pace of development. After all, Banking institutions are committed to contribute their might in building exercise. However, there are few elements common to all such efforts. Quite often, the problems with managing furnarounds are the difficulty of timing and implementing the necessary changes and the inability to convince the management that something drastic needs to be done to remedy the situation. 
Turnarounds are normally associated with near-terminally sick companies. The turnaround organisation, as against a company on a steady course, demands quick and short term problem solving. Companies should look into the need for preparing a contingency plan that will take into account uncommitted liquid cash resources: a program for controlling cash oufflows and investments; and formulating a strategic plan for the manner in which liquidation of plant, equipment or hivingoff of un-remunerative business units should be handled in the event of early warning signals showing up. Such contingency plans should be an integral part of the budgeting process and the overall long-term corporate plan.

Business owners, commercial bankers, equity sponsors and shareholders never expect their company to become financial distressed. In reality, every company has a life cycle, and, at some point, crisis or financial distress should be expected.

\section{References}

1. Ahluwalia, L., and Little, I., M.D., (1998), Introduction, India's Economic Reforms and Development : Essays for Manmohan Singh, Oxford University Press, New Delhi, pp 1-20

2. Central Statistical Organisation National Accounts statistics: Various issues' Department of Statistics, Minisiry of Planning and Program implemention, Government of India 3. Dhar, P.N., (2003). The evolution of economic policy in India: Oxford Universify Press, New
Delhi, ppl-20

4. Economic Times, 2003, Union Budget 01-02, speech of the Finance Minister, Economic Times

5. Government of India, (1999), Economic survey 98-99, Ministry of Finance, New Delhi

6. Government of India, (1999), Economic survey 98-99, Ministry of Finance, New Delhi.

6. Government of India, (1999), Annual report

7. Government of India, (2001), Annual report

8. IMF (1996), Financial Market Challenges and economic performance in developing countries, Box3, world economic outlook, October, IMF, page 62-63

9. Kalirajan, K.P and Salim, R.A. (1997), Journal of Industrial Economics, Volume 14, Number 4, December, pp 387-404

10. Modi, K.K., (1998), Post reform challenges, Hindu survey of Indian industries 1998, pp 27 30

11. www.rbi.inv 